Барсегян Вардан Меружанович

Barsegyan Vardan Meruzhanovich

кандидат политических наук,

член Российской ассоциации политической науки

\section{СОЦИАЛЬНАЯ СТРАТИФИКАЦИЯ И ПОЛИТИЧЕСКАЯ СФЕРА: РОЛЬ ВЛАСТИ И ГОСУДАРСТВА В СТРУКТУРИРОВАНИИ ОБЩЕСТВА [1]}

\section{Аннотация:}

Какую роль играет государство в структурировании общества и влияет ли оно на тип устоявшейся социальной стратификации? Для ответа на эти вопросы автор проводит анализ современных теорий социальной стратификации: теория П. Сорокина, марксизм и неомарксизм, веберианство и неовеберианство, структурный функционализм, а также теория полей и капиталов П. Бурдье. Таким образом, цель настоящей статьи проанализировать способы концептуализации политической сферы, власти и государства в теориях социальной стратификации. Показано, что роль государства и политической сферы различается при переходе от одной теории к другой: наименьшее внимание им уделяется в веберианстве и неовеберианских моделях социальной стратификации; наибольшая роль политиковластным институтам и отношениям отводится в современных теориях социальной стратификации: этатизма, сословного общества и некоторых интерпретациях концепции П. Бурдье. На базе проведенного анализа систематизированы основные подходы к роли государства ө стратификации общества.

Ключевые слова:

социальная стратификация, политическая сфера, социальное пространство, власть, государство.
PhD in Political Science,

\section{SOCIAL STRATIFICATION AND POLITICAL SPHERE: THE ROLE OF POWER AND STATE IN STRUCTURING THE SOCIETY [1]} Member of Russian Political Science Association

\begin{abstract}
Summary
What role does the state play in structuring the society, and does it affect the type of the established socia stratification? To answer these questions, the author analyzes the modern theories of social stratification: P. Sorokin's theory, Marxism and Neomarxism, Weberianism and Neoweberian, structural functionalism, and the theory of fields and capitals by $P$. Bourdieu. Thus, the purpose of this study is to analyze the ways of conceptualizing the political sphere, power and the state in the theories of social stratification. It is shown that the role of the state and the political sphere differs in the transition from one theory to another. The Weberian and Neo-Weberian models of social stratification pay less attention to these phenomena. The political and powerful institutions and relations have the most important role to play in the modern theories of social stratification: statism, estates society and certain interpretations of the concept of P. Bourdieu. Based on the analysis, the main approaches to the role of the state in the stratification of society are systematized.
\end{abstract}

Keywords: power, state. social stratification, political sphere, social space,

\title{
Введение
}

Государство и политическая сфрера играют большую роль в социальной системе и занимают значительное место в социальной структуре общества. Организующая функция государства прослеживается практически во всех сферах общественной жизни, включая экономику, культуру, науку и т. д. Занимая столь заметное место в жизни общества, политическая сфера, однако, не входит в «обычный» набор предметов современных исследований социальной мобильности и социальной стратификации. Цель статьи - проанализировать способы концептуализации политической сферы, власти и государства в теориях социальной стратификации. Исследование позволило наметить возможные пути развития теорий социальной стратификации и мобильности

Для достижения цели необходимо заново вслед за классиками и современными учеными собрать теории социальной мобильности и стратификации для того, чтобы понять, из каких элементов эти теории сконструированы и какая роль в них отводится политической сфере. Анализируя социальную мобильность и социальную стратификацию, следует иметь в виду некоторые тезисы, выдвинутые П. Сорокиным [2], которые обычно принимаются по умолчанию. Резюмируя их, можно сказать, что между людьми по аналогии с географической дистанцией существует дистанция другого рода - социальная. Совокупность всех дистанций составляет социальное пространство. Перемещения внутри него называются социальной мобильностью. Социальное пространство в свою очередь может быть организовано иерархически, тогда тип такой организации можно назвать социальной стратификацией. В качестве иерархизующего элемента могут выступать власть, собственность, деньги, образование, профессия, престиж и т. д. Нужно помнить, что теоретически возможно существование однородного социального пространства с одинаковой дистанцией между всеми индивидами. Однако еще ни одним эмпирическим исследованием данная гипотеза подтверждена не была. 
При изучении социальной стратификации в России необходимо иметь в виду факт, что государство продолжает оказывать сильное влияние на социальную структуру. Если не учитывать фактор государства, то в полученных результатах будет заключен искажающий эффект «игнорирования» этого значимого фактора, как сверхмассивные тела искривляют пространство вблизи себя, где даже параллельные линии начинают пересекаться. Далее перейдем к вопросу о том, как современные концепции учитывают роль государства в социальной стратификации.

Для П. Сорокина термин «социальная стратификация» - это общий родовой термин, указывающий на некое иерархическое устройство социального пространства. Социальная стратификация реализуется через следующие основные формы: экономическую, профессиональную и политическую. Таким образом, П. Сорокин первым применил формулировку «политическая стратификация» для обозначения относительно автономной сферы общества, в рамках которой преобладают отношения господства и подчинения, где есть управляемые и управляющие [3]. Однако роль политической сферы в структурных исследованиях выделяли и другие авторы.

Государство и социальная структура: концепции К. Маркса и М. Вебера

В рамках классического марксизма государство представляет собой временную надстройку над экономической жизнью, которая позволяет господствующим классам - собственникам средств производства (буржуазии) - подавлять и эксплуатировать классы, лишенные собственности на средства производства (главным образом пролетариат) [4]. На первый план здесь выходит классовый конфрликт на основании контроля над средствами производства, соответственно, главным критерием социальной стратификации является критерий экономический.

Современные неомарксистские исследования, обогатив классовую теорию Маркса привнесением в нее профессиональных управленцев, лишенных собственности на средства производства, не обозначают структурирующую роль государственного аппарата по отношению к устройству общества [5]. Другие авторы, основываясь на материале обществ Западной Европы, США и Канады, показывают, что государство лишь в прошлом имело большое влияние на социальную структуру. Обычно такой анализ хронологически заканчивается с выделением роли государства в странах бывшего социалистического лагеря [6, с. 16; 7].

Явное выделение политической власти и, соответственно, политической сферы в социальной стратификации можно найти у М. Вебера, который представлял власть как одну из трех главных осей дифференциации общества наряду с собственностью и престижем [8]. Однако в дальнейшем в рамках неовеберианского анализа социальной структуры был развит экономический подход с выделением в качестве значимого структурирующего фактора отношения к средствам производства (что мы наблюдали также в марксовом и неомарксистском анализе) и разных типов контрактов и рыночных шансов индивидов, имеющих различные навыки [9]. Таким образом, роль государства и политической сферы ни в веберовской, ни в неовеберианской моделях социальной стратификации не раскрывается.

\section{Структурно-функциональные подходы: этатизм и сословное общество}

Среди исследований современных ученых можно назвать несколько попыток введения «государства» в концепции социальной стратификации. Это концепции этакратического общества О.И. Шкаратана и В.В. Радаева [10] и концепция сословного общества С.Г. Кордонского, в основании которых лежит главным образом структурно-функциональный подход.

Основная идея концепции этакратического общества заключается в том, что в качестве центрального критерия расслоения индивидов в обществе выступает доступ к власти: чем большей властью (причем не только политической) обладает человек, тем выше в социальной иерархии он находится [11]. В исторических исследованиях СССР тип этакратического общества чаще всего определяется как государственный социализм. После развала СССР в современной России разрабатывается концепция неоэтакратического общества [12]. В данных теориях роль государства более заметна, однако если исходить из их главной посылки, то мы совершим ту ошибку, о которой предупреждал еще П. Сорокин: мы подменим одну из систем стратификации в обществе, гипертрофировав лишь одно основание социальной стратификации в ущерб другим, не менее значимым, таким образом подменив сложную систему социальной стратификации одномерной политической стратификацией [13]. Более того, когда в качестве главного критерия стратификации в обществе применяется доступ к власти (в широком смысле слова), то большинство населения оказывается в нижнем слое: при любом способе подсчета лишь небольшая часть населения так или иначе причастна к сфере распределения власти, включая власть экономическую, по логике этакратической концепции социальной структуры остальная часть населения - это социальные низы.

Обращаясь к опыту недавнего прошлого нашей страны, нельзя не затронуть пласт исследований, в которых также значимо оценивались место государства и его структурирующая роль в социальной системе социалистических стран. Ученые отмечали, что, несмотря на официально «привилегированное» положение пролетариата в социалистических странах, реальным господ- 
ствующим классом там являлись государственные бюрократы - номенклатура [14]. Группу правящих высших и средних бюрократов М. Джилас называет «новым классом» [15]. Причем номенклатура, или новый класс, не просто пользовалась привилегированным положением, но активно действовала, чтобы его сохранить.

Другая концепция социальной стратификации российского общества, позволяющая включить государство в социальную структуру, - это теория сословного общества С.Г. Кордонского [16]. Главная идея данной теории заключается в том, что индивиды в нашем обществе распределены по социальной иерархии на основании тех функций, которые они выполняют для сохранения целостности государства, т. е. нейтрализации угроз его существования. Например, есть угроза внешней интервенции, для ее нейтрализации создаются армия, министерство обороны, вводятся военные чины и т. д. Чем существеннее риск в глазах верховного арбитра (президента), тем более высокое положение занимают люди, подавляющие эту угрозу. Однако в данной концепции мы наблюдаем, что всего чуть более 5 \% населения так или иначе относятся к «власти», а остальные 95 \% - формируют «народ», «активное население» (предприниматели) и «маргиналы» (криминал и т. п.) [17]. Исследователи сами осознают подобный дисбаланс в распределении власти, поэтому С.Г. Кордонский вводит категории жизни «в реальности» и «на самом деле». То, как протекает жизнь, по мнению самих представителей власти в России, он называет жизнью «в реальности», а то, как живут люди вне поля властных отношений и государственного регулирования, - жизнью «на самом деле» [18].

Таки образом, классовые теории (как неомарксистские, так и неовеберианские) практически не учитывают организующую роль государства в социальной структуре. Концепции этакратического и сословного общества, наоборот, придают гипертрофированное значение политической власти, в результате чего вынуждены (например, в рамках теории сословного общества) предлагать конструкты теневой жизни - России «на самом деле», чтобы включить подавляющее большинство населения в качестве активных субъектов социальной действительности.

\section{Государство и теория капиталов: концепция П. Бурдье}

В связи с этим, по нашему мнению, теории социальной стратификации и мобильности нуждаются в обогащении современными достижениями социологов, что позволит найти адекватное место для политической сореры. Важный вклад в проблематику вносит теория капиталов П. Бурдье [19]. Капитал в широком смысле представляет собой некую ценность, которую можно использовать для получения прибавочной ценности. Исследователь различал экономическую, культурную и социальную формы капитала [20]. В развитие идей П. Бурдье В. Радаев предложил расширенную версию фрорм капиталов: экономический, физический, культурный, человеческий, социальный, административный, политический и символический [21]. Таким образом, место человека в социальной структуре определяется общим объемом и структурой капитала, которым он обладает [22].

Концепция П. Бурдье заманчива тем, что на первый взгляд кажется простым решением вопроса о социальной структуре: действительно, теория капиталов позволяет построить многомерную систему социальной стратификации, учесть многочисленные аспекты сложного устройства общества. Однако, если рассмотреть виды капитала, выделенные П. Бурдье и развитые В. Радаевым, можно отметить, что они, с одной стороны, совершенно разнородны, с другой выступают как значимые только в ограниченных лакунах социального пространства. Ни одна из выявленных форм капитала самостоятельно не определяет место человека в социальной системе, а математическое сложение фрорм капитала и результаты таких операций в исследованиях, на наш взгляд, дают не вполне удовлетворительный результат, поскольку создается впечатление, что выявленные «классы» остаются лишь «классами на бумаге» [23, с. 72].

Возможное решение вопроса о соотношении социальной стратификации и политической сореры может дать концепция полей П. Бурдье: «Каждое поле является местом более или менее декларированной борьбы за определение легитимных принципов деления поля» [24, с. 31], т. е. общество состоит из полей науки, экономики, политики, литературы и т. д. Каждое из них дифференцировано определенным образом на основании обладания индивидами теми или иными ресурсами (капиталами). Таким образом, можно проанализировать социальную стратификацию политического поля, в котором основным капиталом служит объем власти. Данная концепция созвучна теории подсистем общества Т. Парсонса с главными проводниками коммуникаций в них: в частности, власть выступает центральным проводником коммуникации в политической подсистеме [25].

Соответственно, при изучении социальной мобильности в обществе необходимо сначала ответить на вопрос: какой тип социальной стратификации преобладает в обществе и какие группы (классы, страты, сословия и т. д.) при этом возникают. Уже затем следует анализировать переход из одной группы в другую. Поэтому в исследованиях социальной мобильности первичным является определение типа социальной стратификации.

\section{Заключение}

Итак, мы проанализировали основные теории социальной стратификации и показали роль властных отношений и государства в них. Резюмируя, можно сделать следующие выводы. 
1. Государство в стратификационных исследованиях может рассматриваться в следующих вариантах: 1) одна из подструктур общества, мало влияющая на общий тип социальной стратификации, либо понятие государства совпадает с понятием общества и таким образом государственное влияние также нивелируется (структурный функционализм); 2) непосредственно структурирующий элемент общества, имеющий собственные цели и интересы (О.И. Шкаратан, М. Восленский, М. Джилас); 3) инструмент в руках других групп людей (марксизм).

2. Политическая власть в исследованиях социальной стратификации рассматривается с двух сторон: 1) как главный критерий стратификации (О.И. Шкаратан, С.Г. Кордонский); 2) как одно из возможных оснований стратификации наряду с другими (М. Вебер, П. Бурдье).

3. Политическая сфрера также выражена в нескольких фрормах: 1) максимально расширяется и совпадает со всей социальной сферой - в особенности при исследованиях государственного социализма или этакратизма (О.И. Шкаратан), в данном случае более уместно говорить о политико-административной системе, когда решения принимаются политическим руководством, но реализация решения обязательна и принудительна для всего общества; 2) представляется как относительно автономная область жизни общества (структурный функционализм в версии Т. Парсонса, П. Сорокина, П. Бурдье).

4. В веберианских, особенно неовеберианских, исследованиях роль власти, государства и политической сфреры не выделяется и не подчеркивается ввиду фокусирования внимания на рыночных шансах, разных типах контрактов и способностях индивидов.

Таким образом, для изучения роли политической сферы, власти и государства в социальной стратификации и мобильности исследователю необходимо ответить на вопросы, касающиеся следующих категорий:

- власть: 1) центральный критерий социальной стратификации (часто такие исследования маркируются как политическая стратификация); 2) один из факторов социальной стратификации при наличии других главных оснований;

- политическая сфера: 1) автономная область общества со своими законами и системой стратификации; 2) не выделяется как автономная и представляется наряду с экономической, культурной и иными неотделяемой частью общества, в этом случае анализ социальной стратификации проходит сквозной линией через все сферы общества без выделения какой-либо главной;

- государство: 1) рамка автономного социального мира, что по сути делает понятия государства и общества тождественными; 2) часть общества, значимый игрок в социальной жизни и активный структурирующий элемент социальной системы.

В завершение считаем важным отметить, что социальное пространство - это постоянно изменяющийся объект. Соответственно, те формы и значения социального неравенства, которое часто принимает вид социальной стратификации, т. е. структурного ограничения прав и доступа к ценным ресурсам, тоже трансформируются. То, что раньше принималось как неизбежная и необходимая данность, например право собственности на людей, система рабства и т. д., сегодня практически изжило себя, но зато появились другие формы и виды стратификации. В конечном счете любая позиция в социальном пространстве всегда определяется относительно другой позиции: без обездоленных не может быть и благополучных. Именно эта взаимная определенность, с одной стороны, создает иллюзию статичности социальной системы, но с другой - показывает возможные пути снижения социальной напряженности и уменьшения социального неравенства: каждый член общества вне зависимости от занимаемого социального положения зависит от других членов общества.

\section{Ссылки и примечания:}

1. Работа выполнена при финансовой поддержке РФФИ, грант № 17-33-01034 (а2) «Факторы карьерной мобильности в политической деятельности в современной России».

2. Сорокин П.А. Человек. Цивилизация. Общество : пер. с англ. / под ред. А.Ю. Согомонова. М., 1992. 543 с.

3. Там же.

4. Энгельс Ф. Анти-Дюринг. Переворот в науке, произведенный господином Евгением Дюрингом (сентябрь 1876 - июнь 1878 г.) // Маркс К., Энгельс Ф. Полное собрание сочинений. Т. 20. М., 1961.

5. Wright E.O. Approaches to Class Analysis. Cambridge, 2005.

6. Тихонова Н.Е. Социальная структура России: теории и реальность. М., 2014. 408 c.

7. Grusky D. The Past, Present, and Future of Social Inequality // Social Stratification. Class, Race, and Gender in Sociological Perspective. Boulder, 2001. P. 3-51.

8. Вебер М. Основные понятия стратификации // Социологические исследования. 1994. № 5. С. 147-156 ; Weber M. On charisma and institutional building. Chicago ; L., 1968. P. 169-183.

9. Erikson R., Goldthorpe J.H. The Constant Flux: A Study of Class Mobility in Industrial Societies. Oxford, 1992.

10. Правда, теперь В.В. Радаев отмечает, что термин «этакратизм» - это «выдуманное слово, сложенное из французского и греческого корней» и применять его сегодня не стал бы. См.: Радаев В.В. Как организовать и представить исследовательский проект: 75 простых правил. М., 2001. С. 181.

11. Шкаратан О.И. Социология неравенства. Теория и реальность. М., 2012 ; Шкаратан О.И., Ястребов Г.А. Российское неоэтакратическое общество и его стратификация // Социологические исследования. 2008. № 11. С. 40-50. 
12. Шкаратан О.И., Ястребов Г.А. Указ. соч.

13. Сорокин П.А. Указ. соч.

14. Восленский М.С. Номенклатура. Господствующий класс Советского Союза. М., 1991. 624 с.

15. Джилас М. Новый класс. Нью-Йорк, 1961. 248 с.

16. Кордонский С.Г. Сословная структура постсоветской России. М., 2008. 216 с.

17. Дехант Д., Моляренко О., Кордонский С. Сословные компоненты социальной структуры России [Электронный ресурс] // Отечественные записки. 2012. № 1 (46). URL: http://www.strana-oz.ru/2012/1/soslovnye-komponenty-socialnoystruktury-rossii (дата обращения: 08.12.2017).

18. Кордонский С.Г. Россия. Поместная федерация. М., 2010. 312 с.

19. Бурдье П. Формы капитала // Экономическая социология. 2002. Т. 3, № 5. С. 60-74.

20. Там же. С. 60 .

21. Радаев В.В. Понятие капитала, формы капиталов и их конвертация // Экономическая социология. 2002. Т. 3 , № 4. С. 20-32.

22. Бурдье П. Социология политики / сост., общ. ред. и предисл. Н.А. Шматко. М., 1993. 336 с.

23. Бурдье П. Формы ... С. 72.

24. Бурдье П. Социология социального пространства. М. ; СПб., 2007. 288 с.

25. Parsons T. On the Concept of Influence // Politics and Social Structure. N. Y. ; L., 1969. P. 405-438 ; Idem. On the Concept of Political Power // Sociological Theory and Modern Society. N. Y., 1967. P. 297-354 ; Idem. On the Concept of ValueCommitments // Politics ... P. 439-472 ; Parsons T., Smelser N. Economy and Society. A study in Integration of Economic and Social Theory. L., 1956.

\section{References:}

Bourdieu, P 2002, 'Forms of capital', Journal of Economic Sociology, vol. 3, no. 5, pp. 60-74. https://doi.org/10.17323/17263247-2002-5-60-74.

Bourdieu, P 2007, Sociology of social space, Moscow, St. Petersburg, 288 p., (in Russian).

Bourdieu, P \& Shmatko, NA (comp.) (ed.) 1993, Sociology of politics, Moscow, 336 p., (in Russian).

Dekhant, D, Molyarenko, O \& Kordonsky, S 2012, 'Class components of the social structure of Russia', Otechestvennyye zapiski, no. 1 (46), viewed 08 August 2017, <http://www.strana-oz.ru/2012/1/soslovnye-komponenty-socialnoy-struktury-rossii>, (in Russian).

Djilas, M 1961, The new class, New York, 248 p., (in Russian).

Engels, F \& Marx, K (ed.) 1961, Anti-Dühring. Herr Eugen Dühring' revolution in science (September 1876 - June 1878), complete works, vol. 20, Moscow, (in Russian).

Erikson, R \& Goldthorpe, JH 1992, The Constant Flux: A Study of Class Mobility in Industrial Societies, Oxford.

Grusky, D 2001, 'The Past, Present, and Future of Social Inequality', Social Stratification. Class, Race, and Gender in Sociological Perspective, Boulder, pp. 3-51.

Kordonsky, SG 2008, The class structure in the post-Soviet Russia, Moscow, 216 p., (in Russian).

Kordonsky, SG 2010, Russia. The local federation, Moscow, 312 p., (in Russian).

Parsons, T 1967, 'On the Concept of Political Power', Sociological Theory and Modern Society, New York, pp. 297-354.

Parsons, T 1969a, 'On the Concept of Influence', Politics and Social Structure, New York, London, pp. 405-438.

Parsons, T 1969b,'On the Concept of Value-Commitments', Politics and Social Structure, New York, London, pp. 439-472.

Parsons, T \& Smelser, N 1956, Economy and Society. A study in Integration of Economic and Social Theory, London.

Radaev, VV 2001, How to organize and present a research project: 75 simple rules, Moscow, (in Russian).

Radaev, VV 2002, 'Term of Capital, Forms of Capitals and their Conversion', Journal of Economic Sociology, vol. 3, no. 4, pp. 20-32. https://doi.org/10.17323/1726-3247-2002-4-20-32.

Shkaratan, OI 2012, Sociology of inequality. Theory and reality, Moscow. https://doi.org/10.17323/978-5-7598-0913-5.

Shkaratan, OI \& Yastrebov, GA 2008, 'Russian neo-etacratic society and its stratification', Sotsiologicheskiye issledovaniya, no. 11, pp. 40-50, (in Russian).

Sorokin, PA \& Sogomonov, AYu (transl.) 1992, The Man. Civilization. Society, Moscow, 543 p., (in Russian).

Tikhonova, NE 2014, The social structure of Russia: theory and reality, Moscow, 408 p., (in Russian).

Voslensky, MS 1991, Nomenclature. The ruling class of the Soviet Union, Moscow, 624 p., (in Russian)

Weber, M 1968, On charisma and institutional building, Chicago, London, pp. 169-183.

Weber, M 1994, 'Basic concepts of stratification', Sotsiologicheskiye issledovaniya, no. 5, pp. 147-156, (in Russian).

Wright, EO 2005, Approaches to Class Analysis, Cambridge. https://doi.org/10.1017/CBO9780511488900. 